\title{
MPV Values in Children with Adenoid Hypertrophy and Correlation with Adenoid Size
}

\author{
Esra Akyüz Özkan \\ Department of Pediatrics, Medical Faculty, Bozok University, Yozgat, Turkey \\ Email: esra.akyuz@mynet.com
}

Received 27 December 2015; accepted 11 January 2016; published 15 January 2016

Copyright (C) 2016 by author and OALib.

This work is licensed under the Creative Commons Attribution International License (CC BY). http://creativecommons.org/licenses/by/4.0/

(c) (†) Open Access

\begin{abstract}
Background: Adenoid hypertrophy (AH) leads to chronic upper airway obstruction. Upper airway obstruction may cause pulmonary hypertension and right ventricle dysfunction. Mean platelet volume (MPV) may be used as a marker of platelet activation and it is shown that MPV is related to cardiovascular disorders. We investigated in our study if MPV is correlated with adenoid size and can be used as an indicator of obstruction due to adenoid hypertrophy. Methods: 95 children with AH and 99 healthy controls were enrolled in the study. White blood cell, hemoglobin, platelet, Mean platelet volume (MPV) levels were measured before adenoidectomy. Lateral cephalometric graphs were obtained from all patients to measure adenoid/nasopharynx ratio $(A / N)$. The distance between the outermost point of convexity of adenoid shadow and basiocciput was divided to the distance between sphenobasiocciput and posterior end of the hard palate. A/N ratio and MPV levels have been correlated by using Pearson correlation test. Results: There were 45 male and 50 female patients between the ages of 2 and 14 years (mean age: $6.47 \pm 2.44$ ). There were no significant differences between children with $\mathrm{AH}$ and controls regarding white blood cell, hemoglobin, platelet, MPV and $A / N$ ratio. We didn't detect any correlation between MPV levels and $A / N$ ratio. Conclusion: MPV level was in normal limits in AH children and there was no significant relation between MPV and adenoid severity.
\end{abstract}

\section{Keywords}

Adenoid Size, Adenoid Vegetation, Children, Mean Platelet Volume

Subject Areas: Otorhinolaryngology, Pediatrics

\section{Introduction}

Adenoid hypertrophy (AH) commonly leads to upper airway obstruction, obstructive sleep apnea and hypoxia in 
children [1]. Obstructive sleep apnea causes hypoxia, pulmonary hypertension and right ventricle (RV) dysfunction [2]. Obstructive sleep apnea exists in $1 \%-3 \%$ of children and can occur at any age [3]. The adenoids, like all lymphoid tissue, enlarge when infected. Although lymphoid tissue does act to fight infection, sometimes bacteria and viruses can lodge within it and survive. Chronic infection, either viral or bacterial, can keep the pad of adenoids enlarged for years, even into adulthood. Some viruses, such as the Epstein-Barr Virus, can cause dramatic enlargement of lymphoid tissue. Primary or reactivation infections with Epstein Barr Virus, and certain other bacteria and viruses, can even cause enlargement of the adenoidal pad in an adult whose adenoids had previously become atrophied. Enlarged adenoids can become nearly the size of a ping pong ball and completely block airflow through the nasal passages. Even if enlarged adenoids are not substantial enough to physically block the back of the nose, they can obstruct airflow enough so that breathing through the nose requires an uncomfortable amount of work, and inhalation occurs instead through an open mouth. Adenoids can also obstruct the nasal airway enough to affect the voice without actually stopping nasal airflow altogether [4].

Platelet size is correlated with platelet activation and large platelets have more hemostatic activation [5]. So mean platelet volume (MPV) may be used as a marker of platelet activation and may also be associated with atherosclerosis as a simple assessment tool [6]. MPV levels increase in some conditions such as hypertension, hypercholesterolemia, diabetes mellitus, acute myocardial infarction and acute ischemic stroke [7]. Varol et al. [8] suggested that MPV levels were higher in adult patients with severe obstructive sleep apnea than healthy patients. Sagit et al. [9] showed that patients with septal deviation had increased MPV levels. Onder et al. [10] revealed no significant relation between MPV levels and obstructive adenoid hypertrophy.

There are conflicting studies on MPV levels in patients with obstructive conditions. So we aimed to investigate the MPV levels in AH patients and the relationship between MPV levels and adenoid size in children.

\section{Methods}

The current study consisted of 95 patients presented to the pediatrics outpatient clinic of Bozok University Medical faculty with AH (45 male, 50 female; mean age: 6.47 years).

Children with nasal septal deviation, sinonasal infection, hematological disease, chronic diseases, and history of previous adenoidectomy were excluded from the study

Routine preoperative blood samples were drawn from the antecubital vein by careful vein puncture. Blood samples were collected in EDTA, and laboratory data were screened via a computerized database in the hospital. The reference values for MPV ranged between 5.0 and $15.0 \mathrm{f} \mathrm{L}$.

Lateral cephalometric graphs were obtained from all patients to measure adenoid/nasopharynx $(A / N)$ ratio. $\mathrm{A} / \mathrm{N}$ ratio has been shown to have a good correlation with endoscopic examination findings [11]. A/N ratio was calculated as defined by Fujioka et al. [12] before. The distance between the outermost point of convexity of adenoid shadow and basiocciput was divided to the distance between sphenobasiocciput and posterior end of the hard palate.

\section{Statistical Analyses}

The statistical analyses were carried out by Statistical Package for Social Sciences (SPSS) 18. Before performing the Student $t$ test, the data was checked for normality of distribution by Kolmogorov-Smirnov test. Variables were expressed as mean $\pm \mathrm{SD}$. Comparisons of variables were performed using unpaired Student $t$ test and Chi-square test. Bivariate associations of the variables were assessed using Pearson's correlation coefficients and $p$ value $<0.05$ was considered indicate statistical significance.

\section{Results}

The AH group consisted of 95 patients ( 50 females and 45 males) with a mean age of 6.47 years, and the control group had 99 patients ( 57 females and 42 males) with a mean age of 5.77 years. There were no significant differences between the study and control groups in terms of age and sex. All characteristics of the AH and control groups, including MPV, hemoglobin, WBC, MCV and MPV are listed in Table 1.

The mean MPV levels were $9.39 \mathrm{f} \mathrm{L}$ in patients with $\mathrm{AH}$ and $9.64 \mathrm{f} \mathrm{L}$ in the control group and there was no statistical differences $(p=0.156)$. The mean ANS level was $0.78 \pm 0.065$ in patients with AH.

There were no correlation between ANS and other parameters by Pearson correlation analysis. 
Table 1. Comparison (mean \pm SD) of clinical characteristics.

\begin{tabular}{cccc}
\hline \multirow{2}{*}{ Variable } & Children with adenoid hypertrophy & Healthy controls & $\boldsymbol{p}$ value \\
\cline { 2 - 3 } & $\mathbf{n}=\mathbf{9 5}$ & $\mathbf{n}=\mathbf{9 9}$ & 0.081 \\
Age (years) & $6.47 \pm 2.44$ & $5.77 \pm 3.10$ & $0.314^{\&}$ \\
Male/female & $45 / 50$ & $42 / 57$ & 0.280 \\
WBC & $8.78 \pm 2.56$ & $9.23 \pm 3.10$ & 0.198 \\
Hb & $12.54 \pm 0.96$ & $12.75 \pm 1.34$ & 0.924 \\
Platelet & $337.74 \pm 81.31$ & $338.82 \pm 76.44$ & 0.409 \\
MCV & $85.98 \pm 7.85$ & $79.82 \pm 4.53$ & 0.156 \\
MPV & $9.39 \pm 1.13$ & $9.61 \pm 0.94$ & \\
\hline
\end{tabular}

Student's t test, ${ }^{\&}$ Chi-square test, $p$ level is significant at the $<0.05$ level. WBC: white blood cell, Hb: hemoglobin, MCV: mean corpuscular volume, MPV: mean platelet volume.

\section{Discussion}

AH causes upper airway obstruction and leads to increased pulmonary hypertension and corpulmonale [13] and also upper airway resistance syndrome by increased upper airway resistance as a result of labored breathing [14]. It is shown that adenotonsillectomy decreases pulmonary arterial hypertension to normal values in children [15]. When sufficient airflow is not meet nasal way, mouth breathing begins and this causes turbulent airflow. The intraluminal air pressure cannot reach the appropriate level to keep the nasopharyngeal and orophayngeal structures open in the supine position; moreover, the bulk of the tongue is displaced backwards by the influence of gravity, obstructing the airway. Therefore, this chain of events results in alveolar hypoventilation, hypoxia, and hypercarbia during sleep [14] [16].

If the children who had AH or tonsillar hypertrophy left untreated, they can experience abnormal orofacial anatomy, poor appetite, growth retardation, aggressive behavior, anxiety, impaired attention, depression, and somatization disorders over the long term [17] [18].

Chronic alveolar hypoxia causes hypoxemic pulmonary vasoconstriction that leads to hypertension and RV heart failure [19] [20]. MPV level is showed to be higher in patients with pulmonary hypertension [21]. MPV shows platelet activity and large platelets are more active and have more prothrombotic potential [9].

In current study we didn't found any differences between AH and healthy controls in terms of MPV level and we didn't detect any relationship between MPV values and adenoid size. One possible reason for this is that the study group included pediatric patients; chronic hypoxia exposure time is shorter in the pediatric population than in adult patients. MPV values in children may not be related to upper airway obstruction. Önder et al. [10] revealed that there was no significant relation between MPV levels and obstructive adenoid hypertrophy consisted with our results. Cevik et al. [22] found that MPV values were significantly lower in patients with nasal polyps than controls. Yilmaz et al. [23] been showed that adenotonsillary hypertrophy causes higher pulmonary artery pressure values and adenotonsillectomy is an effective therapeutic measure in such patients. Varol et al. [24] revealed that six months of CPAP therapy caused significant reductions in median MPV values in adult patients with severe OSA. Sagit et al. [9] found that septoplasty has a curative effect for hypercoagulopathy with reducing MPV values. Kucur et al. [25] found that MPV values were found to be higher in children with AH than controls and there was a significant reduction in MPV levels after adenoidectomy. They demonstrated that MPV levels may indicate the risk of cardiopulmonary diseases. Steiropoulos et al. [26] also reported that patients with chronic obstructive pulmonary disease had high MPV values. In contrast, Çevik et al. [27] suggested that MPV values in children with AH were significantly lower than those in control subjects. It has been suggested that chronic hypoxia causes catecholamine-dependent platelet activation and that this leads to changes in platelet shape with an increase in platelet swelling, leading to an increase in MPV and PDW [28] [29]. Tuncel et al. [30] found that there is no significant difference in MPV values between asthmatic children and control groups.

\section{Conclusion}

MPV values are in normal limits in children with AH and are not correlated with adenoid size. 


\section{References}

[1] Görür, K., Döven, O., Unal, M., Akkuş, N. and Ozcan, C. (2001) Preoperative and Postoperative Cardiac and Clinical Findings of Patients with Adenotonsillar Hypertrophy. International Journal of Pediatric Otorhinolaryngology, 59, 4146. http://dx.doi.org/10.1016/S0165-5876(01)00449-9

[2] Abdel-Aziz, M. (2011) Asymptomatic Cardiopulmonary Changes Caused by Adenoid Hypertrophy. Journal of Craniofacial Surgery, 22, 1401-1403. http://dx.doi.org/10.1097/SCS.0b013e31821cc334

[3] Gislason, T. and Benediktsdóttir, B. (1995) Snoring, Apneic Episodes, and Nocturnal Hypoxemia among Children 6 Months to 6 Years Old. An Epidemiologic Study of Lower Limit of Prevalence. Chest, 107, 963-966. http://dx.doi.org/10.1378/chest.107.4.963

[4] Gates, G. (1996) Sizing up the Adenoid. Archives of Otolaryngology—Head \& Neck Surgery, 122, 239-240. http://dx.doi.org/10.1001/archotol.1996.01890150017004

[5] Martin, J.F., Trowbridge, E.A., Salmon, G. and Plumb, J. (1983) The Biological Significance of Platelet Volume: Its Relationship to Bleeding Time, Platelet Thromboxane B2 Production and Megakaryocyte Nuclear DNA Concentration. Thrombosis Research, 32, 443-460. http://dx.doi.org/10.1016/0049-3848(83)90255-4

[6] Berger, J.S., Eraso, L.H., Xie, D., Sha, D. and Mohler, E.R. (2010) Mean Platelet Volume and Prevalence of Peripheral Artery Disease, the National Health and Nutrition Examination Survey, 1999-2004. Atherosclerosis, 213, 586-591. http://dx.doi.org/10.1016/j.atherosclerosis.2010.09.010

[7] Vizioli, L., Muscari, S. and Muscari, A. (2009) The Relationship of Mean Platelet Volume with the Risk and Prognosis of Cardiovascular Diseases. International Journal of Clinical Practice, 63, 1509-1515. http://dx.doi.org/10.1111/j.1742-1241.2009.02070.x

[8] Varol, E., Ozturk, O., Gonca, T., Has, M., Ozaydin, M., Erdogan, D. and Akkaya, A. (2010) Mean Platelet Volume Is Increased in Patients with Severe Obstructive Sleep Apnea. Scandinavian Journal of Clinical and Laboratory Investigation, 70, 497-502. http://dx.doi.org/10.3109/00365513.2010.520733

[9] Sagit, M., Korkmaz, F., Kavugudurmaz, M. and Somdas, M.A. (2012) Impact of Septoplasty on Mean Platelet Volume Levels in Patients with Marked Nasal Septal Deviation. Journal of Craniofacial Surgery, 23, 974-976. http://dx.doi.org/10.1097/SCS.0b013e31824e2c08

[10] Onder, S., Caypinar, B., Sahin-Yilmaz, A., Toros, S.Z. and Oysu, C. (2014) Relation of Mean Platelet Volume with Obstructive Adenoid Hypertrophy in Children. International Journal of Pediatric Otorhinolaryngology, 78, 14491451. http://dx.doi.org/10.1016/j.ijporl.2014.06.001

[11] Caylakli, F., Hizal, E., Yilmaz, I. and Yilmazer, C. (2009) Correlation between Adenoid-Nasopharynx Ratio and Endoscopic Examination of Adenoid Hypertrophy: A Blind, Prospective Clinical Study. International Journal of Pediatric Otorhinolaryngology, 73, 1532-1535. http://dx.doi.org/10.1016/j.ijporl.2009.07.018

[12] Fujioka, M., Young, L.W. and Girdany, B.R. (1979) Radiographic Evaluation of Adenoidal Size in Children: Adenoidal-Nasopharyngeal Ratio. American Journal of Roentgenology, 133, 401-404. http://dx.doi.org/10.2214/ajr.133.3.401

[13] Redding, G.J. (1993) Pulmonary Hypertension and Corpulmonale in Children. In: Hilman, B.C., Ed., Pediatric Respiratory Diseases: Diagnosis and Treatment, Vol. 1, Saunders, Philadelphia, 335-353.

[14] Potsic, W.P., Pasquariello, P.S., Baranak, C.C., Marsh, R.R. and Miller, L.M. (1986) Relief of Upper Airway Obstruction by Adenotonsillectomy. Otolaryngology—Head and Neck Surgery, 94, 476-480. http://dx.doi.org/10.1177/019459988609400412

[15] Martha, V.F., Moreira Jda, S., Martha, A.S., Velho, F.J., Eick, R.G. and Goncalves, S.C. (2013) Reversal of Pulmonary Hypertension in Children after Adenoidectomy or Adenotonsillectomy. International Journal of Pediatric Otorhinolaryngology, 77, 237-240. http://dx.doi.org/10.1016/j.ijporl.2012.11.006

[16] Sie, K.C., Perkins, J.A. and Clarke, W.R. (1997) Acute Right Heart Failure Due to Adenotonsillar Hypertrophy. International Journal of Pediatric Otorhinolaryngology, 4, 53-58. http://dx.doi.org/10.1016/S0165-5876(97)00034-7

[17] Tatlipinar, A., Duman, D., Uslu, C. and Egeli, E. (2011) The Effects of Obstructive Sleep Apnea Syndrome Due to Adenotonsillar Hypertrophy on the Cardiovascular System in Children. The Turkish Journal of Pediatrics, 53, 359363.

[18] Li, H.Y. and Lee, L.A. (2009) Sleep-Disordered Breathing in Children. Chang Gung Medical Journal, 32, $247-257$.

[19] Duman, D., Naiboglu, B., Esen, H.S., Toros, S.Z. and Demirtunc, R. (2008) Impaired Right Ventricular Function in Adenotonsillar Hypertrophy. The International Journal of Cardiovascular Imaging, 24, 261-267. http://dx.doi.org/10.1007/s10554-007-9265-1

[20] Abd El-Moneim, E.S., Badawy, B.S. and Atya, M. (2009) The Effect of Adenoidectomy on Right Ventricular Performance in Children. International Journal of Pediatric Otorhinolaryngology, 73, 1584-1588.

http://dx.doi.org/10.1016/j.ijporl.2009.08.013 
[21] Varol, E., Uysal, B.A. and Ozaydin, M. (2011) Platelet Indices in Patients with Pulmonary Arterial Hypertension. Clinical and Applied Thrombosis-Hemostasis, 17, E171-E174. http://dx.doi.org/10.1177/1076029610379400

[22] Çevik, C., Yengil, E., Akbay, E., Arlı, C., Gülmez, M.I. and Akoğlu, E. (2013) Comparison of Mean Platelet Volume Values between Patients with Nasal Polyp and Healthy Individuals. Türk Otorinolarengoloji Arşivi, 51, 106-109.

[23] Yilmaz, M.D., Onrat, E., Altuntaş, A., Kaya, D., Kahveci, O.K., Ozel, O., Dereköy, S. and Celik, A. (2005) The Effects of Tonsillectomy and Adenoidectomy on Pulmonary Arterial Pressure in Children. American Journal of Otolaryngology, 26, 18-21. http://dx.doi.org/10.1016/j.amjoto.2004.06.008

[24] Varol, E., Ozturk, O., Yucel, H., Gonca, T., Has, M., Dogan, A. and Akkaya, A. (2011) The Effects of Continuous Positive Airway Pressure Therapy on Mean Platelet Volume in Patients with Obstructive Sleep Apnea. Platelets, 22, 552-556. http://dx.doi.org/10.3109/09537104.2011.578182

[25] Kucur, C., Kulekci, S., Zorlu, A., Savran, B., Oghan, F. and Yildirim, N. (2001) Mean Platelet Volume Levels in Children with Adenoid Hypertrophy. Journal of Craniofacial Surgery, 25, e29-e31. http://dx.doi.org/10.1097/SCS.0b013e3182a2eddd

[26] Steiropoulos, P., Papanas, N., Nena, E., Xanthoudaki, M., Goula, T., Froudarakis, M., Pita, E., Maltezos, E. and Bouros, D. (2013) Mean Platelet Volume and Platelet Distribution width in Patients with Chronic Obstructive Pulmonary Disease: The Role of Comorbidities. Angiology, 64, 535-539. http://dx.doi.org/10.1177/0003319712461436

[27] Cengiz, C., Erhan, Y., Murat, T., Ercan, A., Ibrahim, S., Ihsan, G. and Ertap, A. (2013) Values of Mean Platelet Volume in Patients with Chronic Tonsillitis and Adenoid Hypertrophy. Pakistan Journal of Medical Sciences, 29, 569572.

[28] Boos, C.J. and Lip, G.Y. (2007) Assessment of Mean Platelet Volume in Coronary Artery Disease-What Does It Mean? Thrombosis Research, 120, 11-13. http://dx.doi.org/10.1016/j.thromres.2006.09.002

[29] Ziegler, M.G., Nelesen, R., Mills, P., Ancoli-Israel, S., Kennedy, B. and Dimsdale, J.E. (1997) Sleep Apnea, Norepinephrine-Release Rate, and Daytime Hypertension. Sleep, 20, 224-231.

[30] Tuncel, T., Uysal, P., Hocaoglu, A.B., Erge, D.O., Karaman, O. and Uzuner, N. (2012) Change of Mean Platelet Volume Values in Asthmatic Children as an Inflammatory Marker. Allergologia et Immunopathologia, 40, 104-107. http://dx.doi.org/10.1016/j.aller.2011.03.007 